Voix et Images

voixetimages

\title{
Lettre ouverte : « À quand le droit de parole pour les Indiens et les Inuit du Nouveau-Québec? "
}

\section{Claude-Yves Charron}

Volume 4, numéro 3, avril 1979

Louis-Philippe Hébert

URI : https://id.erudit.org/iderudit/200184ar

DOI : https://doi.org/10.7202/200184ar

Aller au sommaire du numéro

Éditeur(s)

Les Presses de l'Université du Québec

ISSN

0318-9201 (imprimé)

1705-933X (numérique)

Découvrir la revue

Citer ce document

Charron, C.-Y. (1979). Lettre ouverte : « À quand le droit de parole pour les Indiens et les Inuit du Nouveau-Québec? ». Voix et Images, 4(3), 555-557.

https://doi.org/10.7202/200184ar d'utilisation que vous pouvez consulter en ligne.

https://apropos.erudit.org/fr/usagers/politique-dutilisation/ 


\section{Lettre ouverte :}

\section{«À quand le droit de parole pour les Indiens et les Inuit du Nouveau-Québec?»}

«Dans nos écrits, débats, discussions, actions, manifestations, portant sur l'avenir du Québec, nous passons presque sous silence les Indiens et les Inuit. Nous les tenons incroyablement absents de nos projets politiques, les refoulant jusque dans l'arrière-pays de notre conscience collective.»

Ce constat, formulé par l'un des rares Québécois à s'être intéressé, pendant plus de vingt ans, aux mythes et récits de nos Indieris et Inuit, exige une réplique, un changement.

Il y aura bientôt deux ans que l'Hexagone et Parti pris publient, en collaboration, un ouvrage de cet ethnologue québécois qui, à plus d'un égard, soulevait de tels manques. Des manques qui, contrairement à ceux de Propp, ne sont plus de l'ordre des princesses enlevées ou des formalistes en mal de structures, chacun dans l'attente d'un beau prince charmant, de son combat avec le dragon, puis du mariage et des nombreux enfants.

Le dragon c'est notre ignorance de ces voisins qui sont, eux aussi, québécois, bien que relevant de régions administratives autres: les réserves du coin de Maingan, de Mistassini, de la baie de James ou de la baie de l'Ungava.

Et, à ce dragon, à cette ignorance nôtre s'ajoute toute une autre série d'obstacles, celle des modes, des «papotages » ou, en d'autres termes, des «métalangages».

La quête du trésor perdu est aujourd'hui encore remplacée par cette quête sacrée, non plus celle du petit catéchisme, mais celle des "structures élémentaires de la signification". Un tel choix, avouons-le, ne risque pas de nous mener très loin, sinon à une condamnation sûre et certaine : celle des clochers et des querelles de clochers ou, pour parler autrement tout en disant la même chose, celle des paradigmes et des conflits de paradigmes (au sens de Kuhn, «évidemment »).

Mais reprenons la chaîne, celle que nous avons aux pieds, le gauche et le droit, à son premier maillon: "dans nos écrits, débats, discussions, 
manifestations, portant sur l'avenir du Québec, nous passons presque sous silence les Indiens et les Inuit».

Ce constat de Rémi Savard appelle une réponse, un «feed-back». Mais lequel?

L'accusation qui est en cause nous laisse dans une position pour le moins inconfortable, au banc des accusés.

Où, dans nos écrits et cie..., tenons-nous compte de leur présence, bien des fois plus vieille que l'lliade ou l'Odyssée et bien des fois plus éloquente que nos sermons télévisés, téléromans grands et «p'tits", ceux du « 2 » comme ceux du «10». Jamais, depuis les 7000 ans qu'ils sont ici, sur ces terres d'avant les réserves, n'ont-ils produit des "chefsd'œuvre" arrivant ailleurs qu'à la cheville de nos grands téléromans...

II arrive parfois que leur présence mette à dure épreuve ces Voix et images de notre pays. Le jour où un inuk m'a demandé de lui expliquer ce qui se passait dans nos téléromans, j'avoue que je n'étais pas tellement fier de ces voix et images-là.

Et quand ce même inuk, un de ces humbles conteurs de la trempe d'un Ferron et d'un Vigneault réunis, a appris que les histoires, la «littérature» s'enseignait dans les universités, et qu'il m'a aussitôt demandé comment on l'enseignait, et ce qu'on y produisait, j'avoue également que, ici encore, j'ai hésité. Et, pour être franc, la quête sacrée des «structures élémentaires de la signification " en a pris un dur coup, en surface comme en profondeur...

II y a pourtant, il est vrai, cette réplique de Pierre Perrault :

Héritiers d'une chrétienté triomphante par la croix et par l'épée, nous vendons sans vergogne au reste du monde nos certitudes grégoriennes ou pops, nos canons et nos skidous et nous regorgeons de bons sentiments pourvu que ça ne change rien à notre plomberie et à notre garde-robe.

Nous achetons les larmes aux yeux une sculpture de Napartuk pourvu qu'il ne nous empêche pas de posséder les mines et les rivières de ses terres.

Et tous les prétextes sont bons pour déplorer la disparition des bons sauvages. Nous allons même jusqu'à les emprisonner dans leur image et à faire de tout le grand nord un immense Saint-Jean-Port-Joli.

Combien d'esquimaux sont maintenant consacrés à l'étrange tâche de mémoriser dans la pierre leur propre disparition.

Par l'astuce du plus grand prétexte, de la seule excuse que nous connaissions : la rentabilité. Parce que ça paie. Mais qui, au juste, je voudrais bien le savoir?

Je crois même le savoir. Au point, je l'avoue, de me sentir mal à l'aise devant le génie incontestable de ta mémoire de pierre, ô $\mathrm{Na}$ partuk, en imaginant tous les marchands anglo-saxons qui nous séparent " (1977:61). 
Parlant de marchandises, et avant d'en arriver à l'exploitation et à l'aliénation, parlons plutôt d'échanges. Serait-il seulement possible de sortir de notre inertie et de notre ignorance face à ces mythes, chants et récits des Indiens et Inuit qui font partie, eux aussi, et depuis bien plus long de temps que nous, des Voix et images de notre pays? Serait-il seulement possible de se mettre, nous aussi, à l'écoute de ces «Singers of Tales», les invitant à participer, par exemple, à la section des chroniques de Voix et images, ce qui ne serait qu'un premier pas?

A quand le droit de parole pour les Indiens et les Inuit du NouveauQuébec? A quand leur participation permise dans nos récits, débats, discussions, actions, manifestations portant sur l'avenir du Québec? Sur l'avenir de ses voix et images?

Quand arrêterons-nous de les refouler jusque dans l'arrière-pays de notre conscience collective?

Claude-Yves Charron, Université du Québec à Montréal. 